\title{
Effects of modulating tone frequency, intensity, and duration on the classically conditioned rabbit nictitating membrane response
}

\author{
E. JAMES KEHOE \\ University of New South Wales, Sydney, Australia \\ B. G. SCHREURS \\ National Institutes of Health, Bethesda, Maryland \\ MICHAELA MACRAE \\ University of New South Wales, Sydney, Australia \\ and \\ I. GORMEZANO \\ University of Iowa, Iowa City, Iowa
}

\begin{abstract}
Theories of conditioning commonly assume that the conditioned stimulus (CS) activates a cascade of internal stimuli that govern the conditioned response (CR) on a moment-by-moment basis. As a means of manipulating the internal stimuli, in the present experiments we conducted delay conditioning using a tone CS of constant intensity and frequency. However, the subjects were tested with tones during which the frequency (Experiment 1) or intensity (Experiment 2) either increased or decreased in a continuous fashion over an 800 -msec period. The experiments revealed that the test stimuli dramatically accelerated the recruitment of the CR. That is, both the initiation and peak of the CR occurred several hundred milliseconds earlier than that seen with the constant tone. CR likelihood and CR amplitude showed modest reductions. A third experiment entailed test manipulations of tone duration, which yielded only small changes in the CR's time course. The results are discussed with respect to real-time mechanisms of classical conditioning and their neural substrates in the encoding of pure tones.
\end{abstract}

The time course of the conditioned response (CR) in the rabbit nictitating membrane (NM) preparation has proved to be a valuable tool in understanding learning at behavioral as well as neural levels. In conditioning with a single conditioned stimulus (CS), the CR is highly attuned to the interval between the onset of the CS and the onset of the stimulus (US). Specifically, initiation of NM closure moves to a point roughly midway through the CS-US interval, and maximal closure - the CR peakremains near the locus of US delivery (e.g., Gormezano, Kehoe, \& Marshall, 1983; Mauk \& Ruiz, 1992; Smith, 1968). Should the CS-US interval be altered, the CR peak disappears and then reappears at the new locus of the US (Coleman \& Gormezano, 1971; Salafia, Martino, Cloutman, \& Romano, 1979). Furthermore, when a sin-

This research was supported by the National Institutes of Health, the National Institute of Drug Abuse Grant DA0-5075-02, National Science Foundation grants, the University of Iowa Foundation (through the generous contributions of D. Boatman, H. Gormezano, S. L. Nusser, and W. G. Nusser) and Australian Research Council Grant AC9231222. Correspondence should be sent to E. J. Kehoe, School of Psychology, University of New South Wales, Sydney 2052, Australia (e-mail: j.kehoe@unsw.edu.au). gle CS is paired with the US at two intermixed intervals, the CR develops two distinct peaks, one located at each locus of US delivery (Kehoe, Graham-Clarke, \& Schreurs, 1989; Millenson, Kehoe, \& Gormezano, 1977).

In neurobehavioral research using the NM preparation, electrophysiological studies have used the CR's distinctive time course to reveal a moment-by-moment correspondence between it and the time course of neural firings at several sites in the brain - for example, the abducens nucleus (Cegavske, Patterson, \& R. F. Thompson, 1979; Young, Cegavaske, \& R. F. Thompson, 1976), accessory abducens nucleus (Disterhoft, Quinn, Weiss, \& Shipley, 1985), hippocampal nuclei (Berger \& R. F. Thompson, 1978; Weisz, Clark, \& R. F. Thompson, 1984), and cerebellar nuclei (Berthier \& Moore, 1986; McCormick \& R. F. Thompson, 1984; Moore \& Berthier, 1987). In lesion studies, the time course of the CR has been used to detect subtle effects. For example, following hippocampectomy, alterations in the CR time course during trace conditioning have been observed, sometimes in conjunction with changes in the gross CR frequency (Moyer, Deyo, \& Disterhoft, 1990; Solomon, Vander Schaaf, Weisz, \& R. F. Thompson, 1986), but not 
always (James, Hardiman, \& Yeo, 1987; Port, Romano, Steinmetz, Mikhail, \& Patterson, 1986).

Despite the advances in our knowledge of the $\mathrm{CR}$ at behavioral and neural levels, the stimulus determinants of the CR are poorly understood. Specifically, it is unclear how the CS controls the CR on a moment-by-moment basis. In delay conditioning, the CS is held constant throughout the CS-US interval. For example, the most common CS is a pure tone of constant frequency and intensity. Perhaps the periodicity of the tone's sine wave is the source of the time base for a CR. However, in trace conditioning, the CS is presented for a period at the beginning of the CS-US interval and is then terminated, leaving a gap without any periodic sensory input before the US.

To explain the time course of CRs, Pavlov (1927, pp. 103-104) postulated that a delay CS gives rise to a sequence of hypothetical stimulus elements. Each element is assumed to acquire its own associative strength according to its contiguity with the US. Similarly, when there is a gap between the CS and US, Pavlov (1927, p. 39) proposed that the CS leaves a persistent "trace." This trace bridges the gap and enables $\mathrm{CR}$ evocation during the gap.

Pavlov's ideas have remained largely intact in subsequent accounts of $\mathrm{CR}$ generation. In conventional conditioning theory, associative strength presumably accrues only at the point of contiguity between the stimulus sequence and the US. Subsequently, anticipatory $\mathrm{CRs}$ are assumed to arise from generalization along time-related dimensions of the stimuli from their point of contiguity to their earlier portions (Gormezano, 1972; Gormezano \& Kehoe, 1981; Hull, 1937, 1943, 1952). In the same vein, recent "real-time" models of CR generation use sequences of hypothetical stimulus elements as a central feature of their computations (Desmond, 1990; Desmond \& Moore, 1988; Grossberg \& Schmajuk, 1989; Sutton \& Barto, 1990).

Because the stimulus sequence is hypothetical, it may seem beyond the reach of the experimenter. However, the sequential stimulus hypothesis has been tested indirectly by superimposing a sequence of external stimuli on the internal sequence. In fact, an external sequence of stimuli can gain some control over CR generation in the rabbit NM preparation (Desmond \& Moore, 1991; Kehoe, Horne, Macrae, \& Horne, 1993; Kehoe \& Napier, 1991b). For example, Kehoe et al. (1993) conducted training in which a sequence of two different 50msec tone pulses signaled the US (CSA-CSB-US). CSA preceded CSB by $250 \mathrm{msec}$, and CSB preceded the US by another $250 \mathrm{msec}$. Thus, the CSA-US interval was $500 \mathrm{msec}$, and the CSB-US interval was $250 \mathrm{msec}$. When the interval between the two CSs was shortened on test trials, the $\mathrm{CR}$ was compressed. Conversely, when the CSA-CSB interval was lengthened, the CR was broadened. In the latter case, peaks appeared at two places - one following CSA by a period equal to the CSA-US interval and another following CSB by the CSB-US interval.
The control over CRs by an external sequence of CSs is encouraging to the sequential stimulus hypothesis. Nevertheless, these findings are only analogue in nature. It is still not clear whether the hypothetical stimuli activated by a single CS operate in the same fashion. Attempts to manipulate the internal sequence for a single CS have not been encouraging. Specifically, Kehoe and Napier (1991a) trained subjects with a 400-msec tone $\mathrm{CS}$ in a delay conditioning paradigm. On test trials, the $\mathrm{CS}$ was truncated to values as short as $12 \mathrm{msec}$. These truncations dramatically reduced CR likelihood, but yielded only small alterations in the CR's time course.

On the basis of those findings, Kehoe and Napier (1991a) concluded that CS onset played a considerable role compared with CS duration in both evocation and timing of the CR. Their conclusion is consistent with the available real-time models. They all assume that stimulus transitions-onset or offset-activate the internal stimulus sequence. However, the models differ in the role they attribute to the ongoing portions of a CS. For example, Grossberg and Schmajuk (1989) attribute all stimulus elements to CS onset and give no role to the ongoing portion of the CS. In contrast, Desmond and Moore (1988) assume that the ongoing portions of the $\mathrm{CS}$ are important in preventing disruption of the stimulus sequence until another stimulus transition.

The present experiments were conducted to determine how sensitive CRs are to the ongoing features of a delay CS. Previous research has revealed that the CR's time course is sensitive to sharp stimulus transitions following CS onset - for example, a second pulse (Kehoe et al., 1993) or CS offset (Desmond \& Moore, 1991). However, other than Kehoe and Napier's (1991a) slim findings, there are few data on the CR's sensitivity to ongoing features of the CS. Accordingly, in the present experiments, the changes following CS onset were continuous in nature. Specifically, in the present experiments we conducted training with a steady-tone CS, but then tested the subjects with tones in which the frequency (Experiment 1) or intensity (Experiment 2) changed in a continuous fashion over the tone's duration.

\section{EXPERIMENT 1}

There were three groups in Experiment 1. On CS-US training trials, they received a pure-tone CS of 500 , 1000 , or $1500 \mathrm{~Hz}$. On CS-alone test trials, the tone varied continuously in frequency. On one third of the test trials, the tone ascended in frequency from 500 to $1500 \mathrm{~Hz}$. On another third of the test trials, the tone descended in frequency from 1500 to $500 \mathrm{~Hz}$. On the remaining third of the test trials, the tone was steady in frequency at the value used on CS-US trials.

Depending on the relative contributions of the tone's onset and its later portions in governing the CR, different outcomes could be predicted. If only tone onset mattered, then CR timing would be unaffected by later features of the test tone. However, if the later portions of the test tone did contribute to the $\mathrm{CR}$, then changes in tonal 
frequency would be expected to alter the CR. Because the test tones differed from the steady tone at nearly every point, the likelihood and overall amplitude of the CR would suffer a generalization decrement. As for the time course of the $\mathrm{CR}$, some modest predictions were possible. When the test tone started at the frequency used in training and then became progressively different, the CR might be initiated with a small delay, but later portions of the CR would be truncated as the usual stimulus sequence became disrupted and generalization became progressively weaker. Conversely, when the starting frequency of the test tone differed from the steady tone, the recruitment of the CR might be delayed until the tonal frequency approached the value used in training. As will be described below, the continuing portions of the CS do influence the CR, but not in the way predicted by a generalization decrement hypothesis.

\section{Method}

Subjects. The subjects were 36 naive, male and female albino rabbits (Oryctolagus cuniculus), each 80-100 days old and weighing approximately $2.2 \mathrm{~kg}$ on arrival from a commercial breeder. The animals had free access to food and water in their individual home cages.

Apparatus. The apparatus and recording procedure for the NM response were patterned after those of Coleman and Gormezano (1971), who detailed modifications of the apparatus described by Gormezano (1966). In brief, each subject was restrained in a Plexiglas box and trained individually in 1 of 12 sound-attenuating, ventilated, lighted chambers fabricated from legal-sized fireproof filing cabinets. In each chamber, there was a speaker mounted $15 \mathrm{~cm}$ anterior to and $10 \mathrm{~cm}$ above the subject's head. The speaker provided the $\mathrm{CS}$, which was a pure tone $800 \mathrm{msec}$ in duration and $82 \mathrm{~dB}$ (SPL) in intensity. The tones were produced by a programmable sine-wave generator (Marshall-Goodell, Frei, \& Gormezano, 1989). The CS was superimposed on an ambient noise level of $55 \mathrm{~dB}$, provided by an exhaust fan. The US was a $50-\mathrm{msec}, 3-\mathrm{mA}$, $60-\mathrm{Hz}$ ac current delivered through 9-mm Autoclip wound clips, positioned $10 \mathrm{~mm}$ apart and $15 \mathrm{~mm}$ posterior to the dorsal canthus of the right eye. On training trials, the CS-US interval (onset to onset) was $800 \mathrm{msec}$. The sequence and timing of stimulus events were controlled by an Apple II computer equipped with interfaces and software developed by Scandrett and Gormezano (1980).

To transduce movements of the NM, a small wire hook was attached to a silk loop sutured into the NM of the rabbit's right eye. The other end of the hook was attached through a ball joint to a photoelectric transducer (Gormezano \& Gibbs, 1988). The signal from the transducer was amplified and transmitted to an ana$\log /$ digital converter installed in the computer.

Procedure. All the rabbits received 1 day of preparation, 1 day of recovery, 1 day of adaptation, and 12 days of training. On the preparation day, hair posterior to the rabbit's right eye was removed for placement of the US electrodes, a small loop of silk (Ethicon 6-0) was sutured into the NM, and the animals were returned to their home cages. On the adaptation day, the animals were placed into the conditioning apparatus for $60 \mathrm{~min}$, but neither a CS nor a US was presented.

Following adaptation, the rabbits were assigned randomly to three groups $(n=12)$, designated as Groups F500, F1000, and F1500. The group labels refer to the frequency of the tone CS on training trials- $-500,1000$, and $1500 \mathrm{~Hz}$, respectively. On each day of training, all the animals received 48 CS-US pairings interspersed with $12 \mathrm{CS}$-alone test trials. Test trials consisted of tone presentations in which the tone frequency either increased in a continuous fashion from 500 to $1500 \mathrm{~Hz}$, decreased from 1500 to
$500 \mathrm{~Hz}$, or remained steady at the frequency used on training trials for the group in question. A test trial was administered every fifth trial. Each type of test trial was presented once in each block of 15 trials. The mean intertrial interval was $60 \mathrm{sec}$ (range, 50-70 sec).

Response definition and statistical analyses. For CS-US trials, a CR was defined as any extension of the NM exceeding $0.5 \mathrm{~mm}$ initiated during the CS-US interval. On CS-alone test trials, a CR was any extension of the NM exceeding $0.5 \mathrm{~mm}$ initiated within $1,600 \mathrm{msec}$ following CS onset. Because the unconditioned response was absent on test trials, the time course of the CR on test trials was characterized by three dependent variables: (1) the onset latency, which was the point at which the CR departed from the NM's resting baseline by $.0625 \mathrm{~mm},(2)$ the CR peak amplitude, which was the maximal extent of NM closure, and (3) the CR peak latency, which was the point in time at which the CR reached its peak amplitude (Marshall-Goodell, Schreurs, \& Gormezano, 1982). Statistical tests were conducted on each of these dependent variables using separate analyses of variance (ANOVAs). Each analysis contained a between-subjects factor, group (three levels), and a within-subjects factor, stimulus (three levels).

\section{Results}

CR acquisition on CS-US trials, which always used the designated steady CS, proceeded similarly in all three groups. The mean percentage on CS-US trials exceeded $50 \%$ by Day 5 of training and reached asymptotic levels of at least $75 \%$ CRs. Figure 1 shows the percentage CRs on test trials for Groups F500, F1000, and F1500. For each group, there is a set of three columns that represents the mean percentage of CRs on test trials using the steady (S), ascending (A), and descending (D) tone frequencies. The means for each type of test trial were collapsed across Days 1-12 of training. Inspection of Figure 1 reveals that for the steady tone, the subjects trained with a $1000-\mathrm{Hz}$ frequency responded at lower levels $(M=53 \%)$ than did the subjects trained with a frequency of $500 \mathrm{~Hz}(M=72 \%)$ or $1500 \mathrm{~Hz}(M=62 \%)$. Furthermore, the levels of responding to the two test

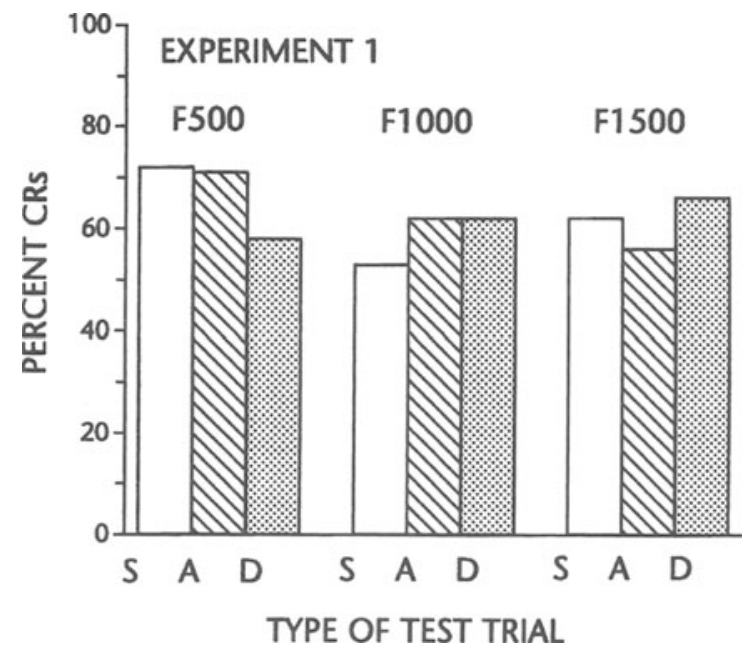

Figure 1. The mean percentage CRs in Experiment 1 on test trials with the steady (S), ascending (A), and descending (D) tone frequencies for Groups F500, F1000, and F1500. Each mean is based on 48 test trials of each type delivered to each subject across Days 1-12. 
tones did not form a consistent pattern across groups. An ANOVA revealed that there was a significant interaction of stimulus $\times$ group $[F(4,66)=13.18, p<.05]$. This interaction appeared to arise from high levels of responding to the increasing and decreasing test tones in Group F1000 relative to lower levels of responding to the steady tone. In contrast, in Groups F500 and F1500, responding to the increasing and decreasing tones was, on average, lower than responding to the steady tone.

Figure 2 depicts the key features of the CR's time course on test trials. There is a separate panel for each group. Within each panel there are three lines, which represent the CRs to the steady (S), ascending (A), and descending (D) test tones. For each line, the left-hand point represents the mean $C R$ onset latency. The CR onset latency has, by definition, a zero amplitude (Marshall-Goodell et al., 1982). The right-hand point in each line shows the mean latency of the CR peak on the $x$-axis and its mean amplitude on the $y$-axis.

Inspection of Figure 2 reveals that both test tones uniformly accelerated the recruitment of the $\mathrm{CR}$ relative to the steady tone in all three groups. The steady tone yielded CRs that were initiated slightly before the halfway point of the $800-\mathrm{msec}$ CS-US interval. Across groups, the mean $C R$ onset latency to the steady tone was $381 \mathrm{msec}$. In contrast, for both test tones, the CR was initiated earlier in the CS-US interval. Across groups, the mean $\mathrm{CR}$ onset latency to the ascending tone was $242 \mathrm{msec}$. Similarly, for the descending tone, the mean CR onset latency was $226 \mathrm{msec}$.

With regard to $C R$ peak latencies, the $C R$ reached its peak on steady-tone trials shortly after the point of US delivery at $800 \mathrm{msec}$ after tone onset. Across all groups, the mean peak latency for the steady tone was $884 \mathrm{msec}$. For the ascending and descending tones, the CR peak appeared near the midpoint of the CS-US interval, well before the point of US delivery. The overall mean CR peak latency was $503 \mathrm{msec}$ on ascending-tone trials and $481 \mathrm{msec}$ on descending-tone trials.

Separate ANOVAs were conducted for onset latency, peak latency, and peak amplitude. They confirmed the observed differences among the types of tones. Specifically, there was a significant main effect of stimulus for onset latency $[F(2,66)=152.84, p<.01]$ and peak latency $[F(2,66)=475.28, p<.01]$. For CR peak amplitude, there was a significant main effect of stimulus $[F(2,66)=13.72, p<.01]$ plus a significant interaction of stimulus $\times$ group $[F(4,66)=6.08, p<.05]$. Examination of Figure 2 indicates that, in all groups, the mean amplitudes of CRs to both test tones were slightly smaller than the CRs evoked by the steady tones. This difference appeared to be greater in Groups F500 and F1000 than in Group F1500.

\section{Discussion}

The results of Experiment 1 demonstrated that variations in frequency after tone onset systematically altered the time course of the CR. Specifically, tests with ascending and descending tones uniformly accelerated the
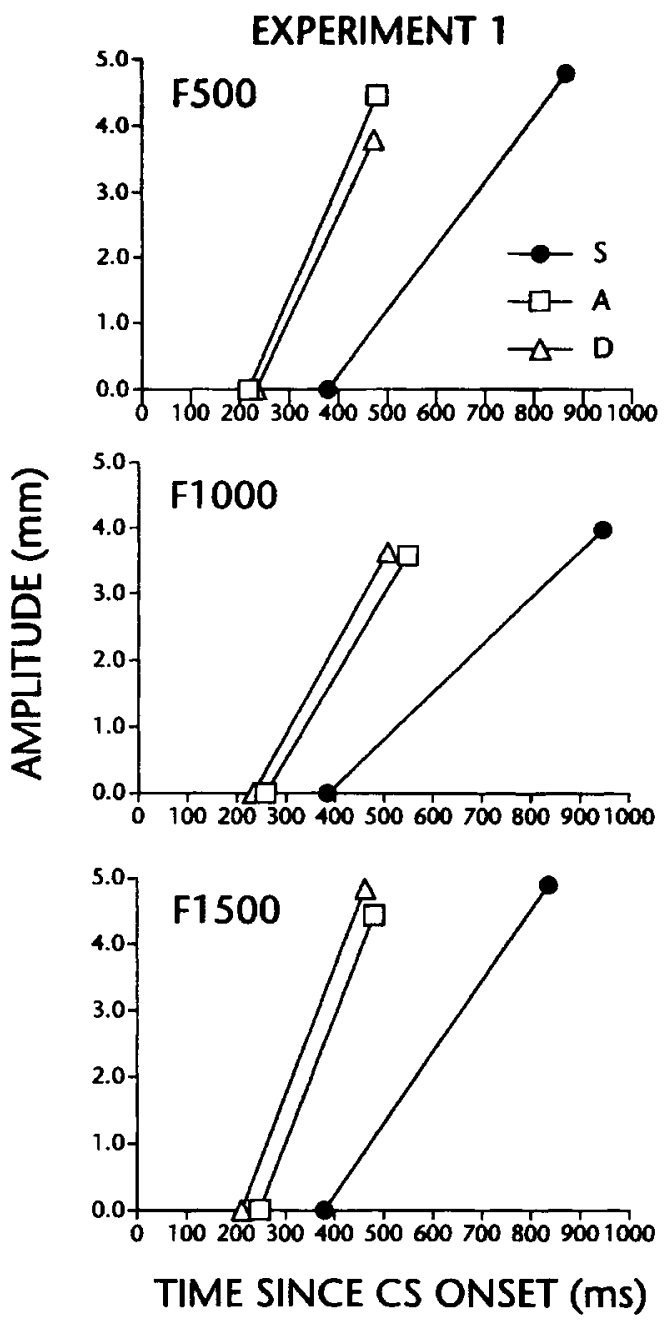

Figure 2. Time course of the CRs in Experiment 1 for Groups $F 500, F 1000$, and $F 1500$. In each panel, there are three lines that represent the CRs to the steady (S), ascending (A), and descending (D) tone frequencies. In each line, the left-hand point represents the mean CR onset latency. The right-hand point in each line shows the mean latency of the CR peak on the $x$-axis and its mean amplitude on the $y$-axis. Each mean is based on $\mathbf{4 8}$ test trials of each type delivered to each subject across Days 1-12.

CRs in all the groups. The changing tonal frequency during the CS seemed to be all that mattered to CR timing, regardless of the direction of change. With regard to CR likelihood and CR amplitude, there was some evidence of incomplete generalization from the steady tone to the test tones. That is, the CR likelihood and CR amplitude tended to be lower during the test tones than the steady tone. However, this generalization decrement did not appear to play a role in CR timing. Had it played a prominent role, there would have been a deceleration in the CRs to the test tones. For example, the descending tone in Group F500 started at $1500 \mathrm{~Hz}$ and did not reach the frequency of the training tone, $500 \mathrm{~Hz}$, until the moment of tone offset. Hence, there should have been a substantial generalization decrement and, accordingly, 
delays in CR initiation and recruitment. Similar delays should have appeared for Group 1500 when tested with the ascending tone, which started at $500 \mathrm{~Hz}$ and ascended to $1500 \mathrm{~Hz}$. Conversely, for CSs that progressively departed from the value used in training, CR initiation should have been slightly delayed, but the later portions should have been truncated, yielding a small and perhaps early peak. According to a generalization decrement hypothesis, this pattern should have appeared for the ascending tone in Group F500 and for the descending tone in Group F1500. In fact, for all test CSs, the entire CR was displaced toward CS onset, and the reduction in peak amplitude was modest.

\section{EXPERIMENT 2}

Experiment 2 was aimed at determining whether or not continuous changes in tone intensity during test trials would have effects similar to those with changes in tone frequency.

\section{Method}

The subjects were 36 naive, male and female albino rabbits. Except where noted, the apparatus and procedure were identical to those used in Experiment 1. All the rabbits received 1 day of preparation, 1 day of recovery, 1 day of adaptation, and 12 days of training. The animals were assigned randomly to three groups $(n=12)$, designated as Groups INT60, INT75, and INT90. The group designations correspond to the intensity of the tone CS on training trials-that is, 60,75 , or $90 \mathrm{~dB}$ (SPL), respectively. All the groups received 12 days of acquisition training. Each day contained 48 CS-US pairings interspersed with $12 \mathrm{CS}$-alone test trials. The test trials consisted of tone presentations in which the tone intensity either ascended from 60 to $90 \mathrm{~dB}$, descended from 90 to $60 \mathrm{~dB}$, or remained steady at the intensity of 60,75 , or $90 \mathrm{~dB}$ used on training trials.

During the experiment, 1 rabbit in Group INT90 died. Its data were excluded from the results.

\section{Results}

All three groups showed CR acquisition on CS-US trials, but, as seen in previous manipulations of tone intensity, the rate of $\mathrm{CR}$ acquisition was a direct function of the intensity of the steady CS (e.g., Kehoe, 1982; Scavio \& Gormezano, 1974). Specifically, responding in Group INT60 grew slowly and reached an asymptote around $65 \%$ CRs. In contrast, Groups INT75 and INT90 showed faster CR acquisition that reached asymptotes of $85 \%$ and $95 \%$ CRs, respectively.

With regard to test trials, Figure 3 shows the percentage CRs for Groups INT60, INT75, and INT90. As was described for the CS-US trials, the overall level of responding was a direct function of the intensity of the steady CS used on CS-US trials. Specifically, percentage CRs on test trials for Groups INT60, INT75, and INT90 were $42 \%, 69 \%$, and $76 \%$ CRs, respectively $[F(2,32)=11.05, p<.01]$. Inspection of Figure 3 reveals a pattern of interaction between the tones and groups $[F(4,64)=6.93, p<.01]$. In Groups INT60 and INT75, responding to the increasing and decreasing tones was much the same as responding to the steady tone. How-

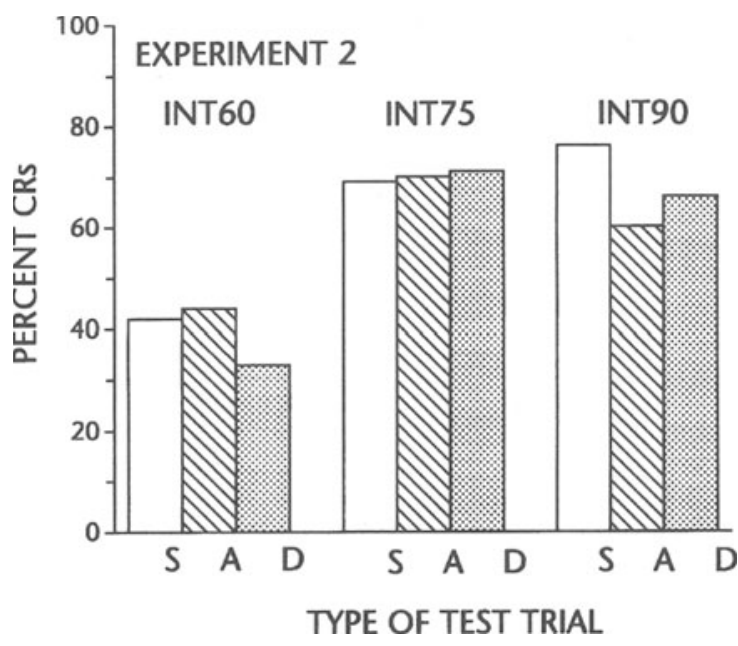

Figure 3. The mean percentage CRs in Experiment 2 on test trials with the steady (S), ascending (A), and descending (D) tone intensities for Groups INT60, INT75, and INT90. Each mean is based on 48 test trials of each type delivered to each subject across Days 1-12.

ever, in Group INT90, the level of responding to the increasing and decreasing tones was lower than the level of responding to the steady tone.

Figure 4 shows the key features of the CR's time course for each group on the trials with the steady (S), ascending (A), and descending (D) intensities. The reader should note that the $y$-axis for CR amplitude differs in its scale across groups. In general, Groups INT60, INT75, and INT90 tended to produce progressively larger CRs.

Inspection of Figure 4 reveals that, in all three groups, the steady tone yielded CRs that were initiated slightly before the halfway point of the 800-msec CS-US interval. Across groups, the mean onset latency to steady tones was $332 \mathrm{msec}$. On steady-tone trials, the $\mathrm{CR}$ reached its peak shortly after the point of US delivery at $800 \mathrm{msec}$ after tone onset. Across groups, the mean peak latency was $843 \mathrm{msec}$.

Relative to the steady tone, the descending tone accelerated the recruitment of the CR. For the descending tone, the CR onset was initiated earlier in the CS-US interval, and the CR peak appeared before the point of US delivery. Across the three groups, the mean onset latencies ranged from $279 \mathrm{msec}$ in Group INT60 down to $144 \mathrm{msec}$ in Group INT90. The peak latencies on descending-tone trials appeared around the midpoint of the CS-US interval. Specifically, the mean peak latencies ranged from $485 \mathrm{msec}$ in Group INT60 down to $388 \mathrm{msec}$ in Group INT90.

For the ascending tone, there was a varied pattern of responding across groups. In Group INT60, there was a pronounced acceleration in the recruitment of the CR; the mean onset latency was $236 \mathrm{msec}$, and the mean peak latency was $458 \mathrm{msec}$. In Group INT75, a more modest acceleration was apparent on ascending-tone trials; the mean onset latency was $291 \mathrm{msec}$, and the peak latency 
EXPERIMENT 2
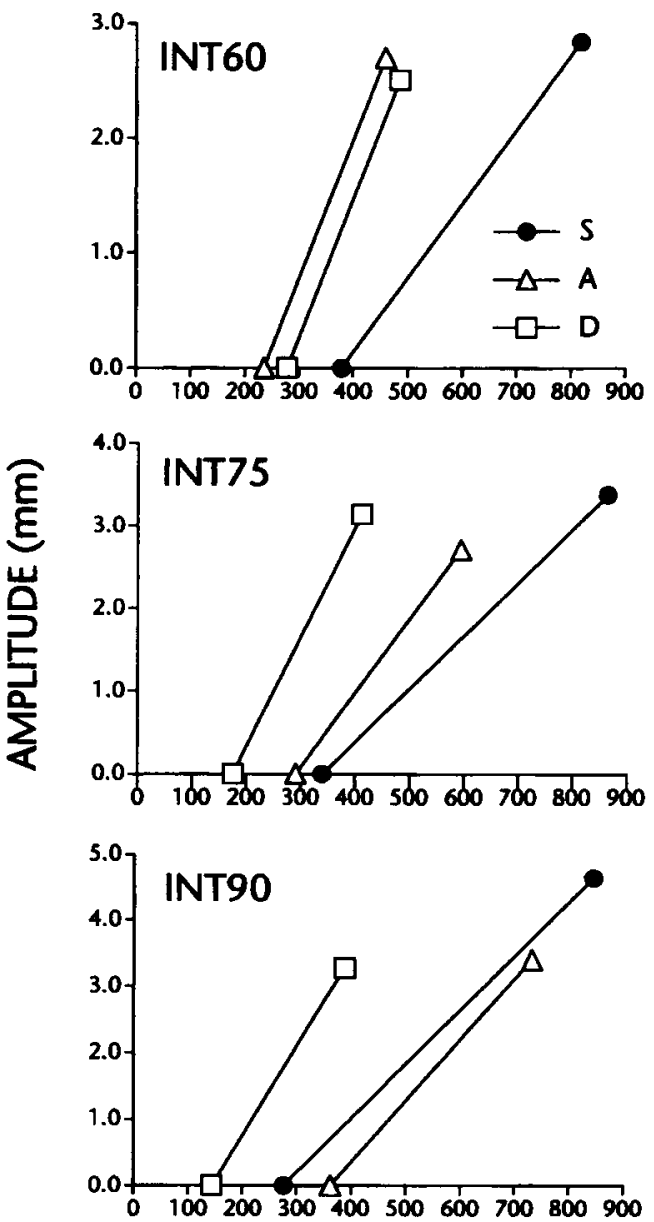

TIME SINCE CS ONSET (ms)

Figure 4. Time course of the CRs in Experiment 2 for Groups INT60, INT75, and INT90. In each panel, there are three lines that represent the mean onset latency, peak latency, and peak amplitude of CRs to the steady (S), ascending (A), and descending (D) test intensities. The $y$-axis for peak amplitude differs in its scale across groups. Each mean is based on $\mathbf{4 8}$ test trials of each type delivered to each subject across Days 1-12.

was 595 msec. In Group INT90, no acceleration appeared on ascending-tone trials. In fact, the onset latency $(M=362 \mathrm{msec})$ was longer than that of CRs on steady tones $(M=276 \mathrm{msec})$. Following the CR's initiation, the CR recruitment on ascending and steady trials followed the same path to the point where the CR on ascending-tone trials reached its peak, which was smaller in amplitude than that on steady-tone trials. Consequently, the CR peak occurred earlier $(M=732 \mathrm{msec})$ on ascending tone trials than on steady-tone trials $(M=$ $846 \mathrm{msec}$ ).

ANOVAs were conducted for onset latency, peak latency, and peak amplitude. They confirmed that there were significant interactions of stimulus $\times$ group for onset latency $[F(4,64)=14.77, p<.001]$ peak latency
$[F(4,64)=19.85, p<.001]$ and peak amplitude $[F(4,64)=$ $6.41, p<.05]$. For CR peak amplitude, the pattern of interaction was similar to that seen with $C R$ likelihood. In Group INT60, the CR amplitude to the increasing and decreasing test tones was much the same as the CR amplitude to the steady tone. In comparison, in Groups INT75 and INT90, CR amplitudes were larger for the steady tones than for the ascending and descending tones.

\section{Discussion}

The pattern of results in Experiment 2 was more complicated than that in Experiment 1. Nevertheless, a changing tone intensity tended to accelerate the CR relative to the steady tone used in training. Specifically, the descending tone produced an acceleration in all the groups. The ascending tone produced a pronounced acceleration in Group INT60, less acceleration in Group INT75, and a slight deceleration in Group INT90.

Although continuous changes in tone intensity usually accelerated the CR, it is unclear how the acceleration is related to the hypothetical stimuli envisaged in current real-time models. With regard to the possibility of generalization decrement, both ascending and descending tones should have activated stimulus elements that differed from those of the steady tone. These elements would have had little or no associative strength. Consistent with a generalization decrement hypothesis, there were some modest reductions in CR peak amplitude for the test tones. However, as was discussed in connection with the effects of tone frequency changes, there should have been pronounced deceleration in at least some cases. Although Group INT90 showed a slight deceleration for the ascending CS, there was no corresponding deceleration in Group INT60 with the descending CS.

Dynamogenic effects of the intensity manipulations may have played some role in the results of Experiment 2, but they do not appear sufficient to explain the findings. In fact, there are two possible dynamogenic effects. First, there is the difference between the average intensities of the test tones and the steady tone. The average intensity of the test tones was $75 \mathrm{~dB}$ (SPL). For Group INT60, this average was higher than that for its steady CS. Thus, as was seen, both test tones accelerated the CR. However, in Group INT75, the average intensity of both test tones equaled the steady tone. Thus, no acceleration would have been expected. Finally, in Group INT90, the average intensity of the test tones was less than that of its steady tone. Thus, a deceleration would have been expected. Instead, an acceleration was seen with the descending tone in Group INT90.

A second dynamogenic effect could arise from the changing nature of the test tone, regardless of its absolute intensity or direction of change. The continuous changes may have effectively increased the intensity of the stimulus elements, perhaps by increasing the overall alertness or arousal of the rabbits. This increase would cause the CR to start earlier and rise more quickly. By 
the same token, however, the CR should have persisted throughout the remainder of the tone. The CR peak still should have occurred around the time of US delivery and not, as was seen, about halfway through the tone.

\section{EXPERIMENT 3}

In Experiments 1 and 2, substantial acceleration of the $\mathrm{CR}$ occurred when the ongoing features of the tone CS were varied in a continuous fashion. These large effects differed dramatically from the modest effects obtained by Kehoe and Napier (1991a) when they either truncated a delay CS or extended a trace CS. In brief, truncation of a 400-msec delay CS to durations of $100 \mathrm{msec}$ or less delayed the onset and peak of the CR by approximately $100 \mathrm{msec}$. Extension of a $100-\mathrm{msec}$ trace CS, which was trained at a $400-\mathrm{msec} \mathrm{CS}-\mathrm{US}$ interval, produced smaller delays, around $70 \mathrm{msec}$. Because Kehoe and Napier (1991a) used a 400-msec CS-US interval, the stimulus elements arising from CS onset may have overshadowed any stimuli arising from the continuing portion of the CS. In contrast, in Experiments 1 and 2, the CS-US interval was $800 \mathrm{msec}$. This interval may have provided a greater opportunity for any stimulus elements arising from the continuing portion of the CS to assert themselves. On the basis of these considerations, in Experiment 3 we examined the results of truncating a delay CS and extending a trace CS when the CS-US interval was $800 \mathrm{msec}$.

\section{Method}

The subjects were 36 naive, male and female albino rabbits. Except where noted, the apparatus and procedure were identical to those used in Experiments 1 and 2. All the rabbits received 1 day of preparation, 1 day of recovery, 1 day of adaptation, and 12 days of training. In all the groups, the CS-US interval on training trials was $800 \mathrm{msec}$, but the duration of the CS differed across groups. Specifically, the animals were assigned randomly to three groups $(n=12)$, designated as Groups D50, D400, and D800. The group labels indicate the CS duration on CS-US training trials50,400 , and $800 \mathrm{msec}$. Thus, Groups D50 and D400 received trace conditioning, and Group D800 received delay conditioning. On each day of training, all the animals received $48 \mathrm{CS}$-US pairings interspersed with $12 \mathrm{CS}$-alone test trials. There were three trials each with CS durations of $50,400,800$, and $1,600 \mathrm{msec}$. A test trial was administered every fourth trial so that one of each trial type was administered in each block of 16 training trials.

During the experiment, 1 rabbit in Group D800 died. Its data were excluded from the results.

\section{Results}

As would be expected from previous findings (e.g., Kehoe \& Schreurs, 1986), the duration of the CS on training trials affected the rate of CR acquisition. Specifically, Group D50, which received trace conditioning using a very brief $C S$, showed the slowest $C R$ acquisition and reached an asymptote of $65 \%$ CRs. Group D400, in which the CS filled the first half of the 800-msec CS-US interval, showed more rapid CR acquisition that reached an asymptote of $95 \%$ CRs. Group D800, which received delay conditioning, also showed rapid CR acquisition and also reached an asymptote of $95 \%$ CRs.

Figure 5 shows the percentage CRs on test trials for Groups D50, D400, and D800 across Days 1-12. Inspection of the figure reveals a pattern of interaction between the test durations and groups $[F(6,96)=15.09, p<$ $.01]$. Specifically, in Group D50, extension of the CS past the 50-msec duration used on training trials had no discernible effect on the likelihood of a CR. The level of responding to all CS durations hovered around $48 \%$ CRs. In the other two groups, foreshortening the CS relative to the training duration did produce reductions in responding. In Group D400, foreshortening the CS to 50 msec produced a drop of $10 \% \mathrm{CRs}$, compared with a mean level of $73 \%$ CRs for the $400-$ msec CS used on training trials. Similarly, Group D800 showed a drop of nearly $30 \%$ CRs when the CS was foreshortened to $50 \mathrm{msec}$ from $800 \mathrm{msec}$. In Groups D400 and D800, extension of the CS to durations longer than that used in training failed to produce a discernible change in $\mathrm{CR}$ likelihood.

Figure 6 depicts the key features of the CR's time course for each group on the different test trials. As is readily apparent in the figure, the durations of the test CS had little if any effect on the time course of the CR. Within each group, the mean onset latencies and mean peak latencies differed by no more than $50 \mathrm{msec}$. The only large and significant difference was a tendency for Group D50 to show longer onset latencies than the other two groups. Specifically, averaged across all test durations, the mean onset latencies for Groups D50, D400, and D800 were 631,470 , and $472 \mathrm{msec}$, respectively. An ANOVA confirmed that there was a main effect of group on the onset latencies $[F(2,32)=5.12, p<.05]$.

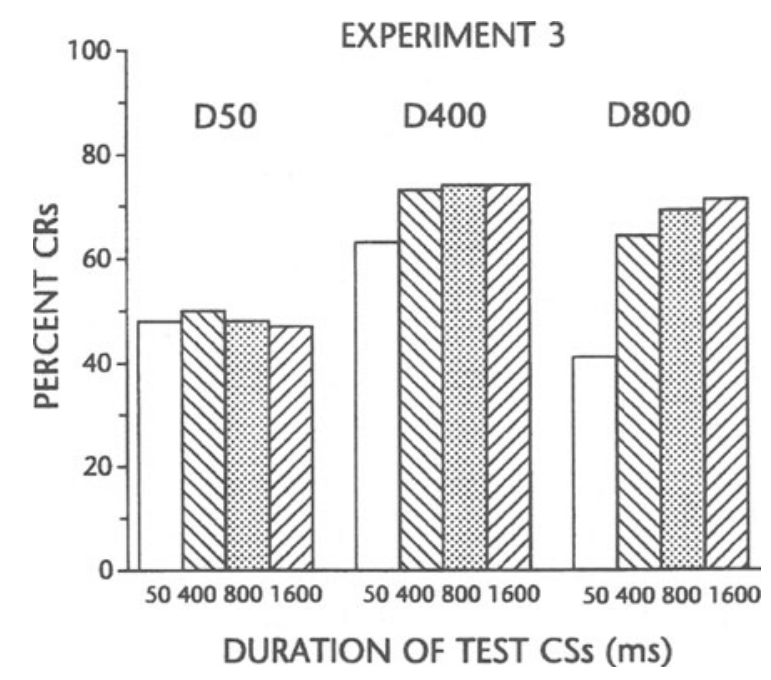

Figure 5. The mean percentage CRs in Experiment 3 on test trials with tone durations of $50,400,800$, and 1,600 msec for Groups D50, D400, and D800. Each mean is based on 48 test trials of each type delivered to each subject across Days 1-12. 

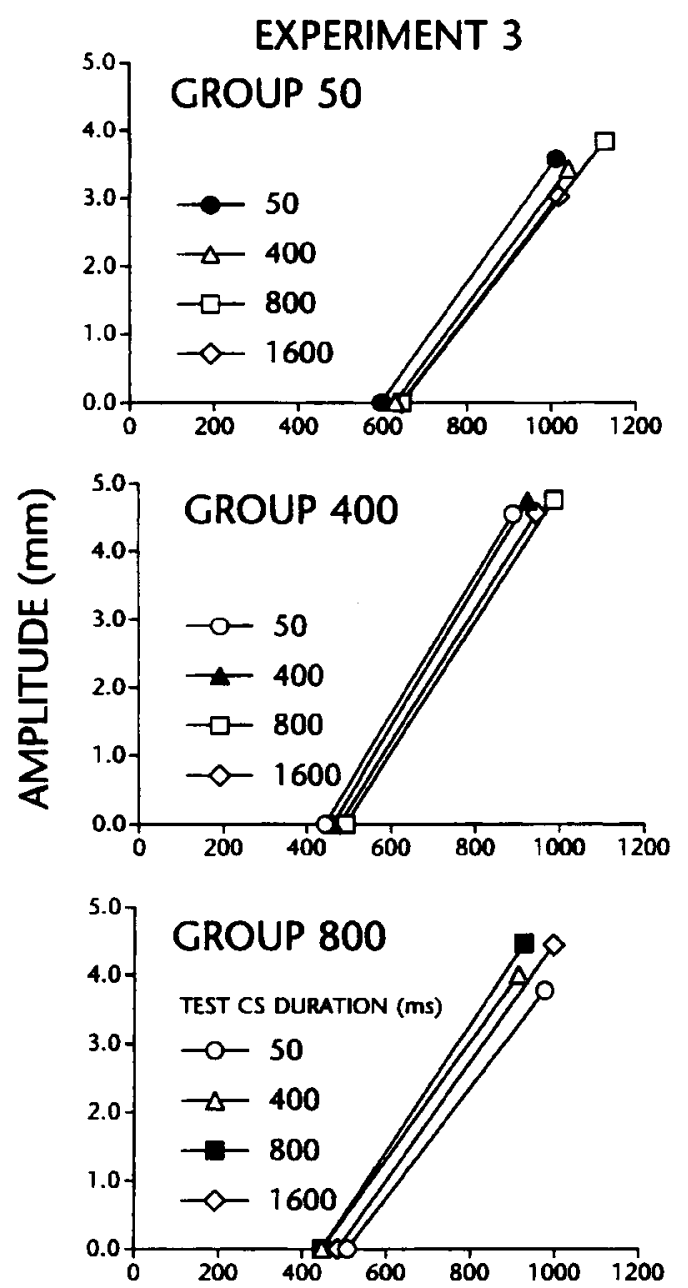

TIME SINCE CS ONSET (ms)

Figure 6. Time course of the CRs in Experiment 3 for Groups D50, D400, and D800. In each panel, there are three lines that represent the mean onset latency, peak latency, and peak amplitude of CRs on trials with tone durations of $50,400,800$, and 1,600 msec. Each mean is based on 48 test trials of each type delivered to each subject across Days 1-12.

There appeared to be only small differences in the CR peak amplitude. However, ANOVAs yielded a significant interaction of test duration $\times$ group $[F(6,96)=$ $3.40, p<.01]$. A close inspection of Figure 6 reveals a pattern similar to that seen for CR likelihood. That is to say, in Group D50, the mean amplitudes were relatively low, but similar across test CSs. In Group D400, the mean amplitudes were larger, but still similar across test CSs. In Group D800, however, there was a tendency for the 50- and 400-msec test CSs to elicit smaller CRs than the 800 - and 1,600-msec CSs.

\section{Discussion}

The results of Experiment 3 strongly resembled those of Kehoe and Napier (1991a). The two sets of results agreed that truncation of a CS tends to reduce CR likelihood and CR amplitude. However, there was little if any impact on the onset latencies or peak latencies. In fact, there was even less in the present experiment than in the earlier results. In conclusion, the $800-\mathrm{msec}_{\mathrm{CS}}-$ US interval used in Experiment 3 did not appear to enhance the opportunity for any hypothetical stimulus elements activated during the ongoing portions of the CS to assert themselves.

\section{GENERAL DISCUSSION}

The present results present a conundrum to sequential stimulus hypotheses of CR generation. At a coarse level, the distortions in the CR's time course show that the CR is under the moment-by-moment control of ongoing features of the CS. Such control is consistent with the hypothesis that an array of distinctive stimulus elements are activated sequentially during the CS (e.g., Desmond, 1990; Pavlov, 1927). However, at a more refined level, the pattern of the distortions does not indicate how CS frequency and CS intensity are encoded on a momentby-moment basis into the stimulus elements. However, as will be discussed below, the sequential stimulus hypotheses can accommodate a wide variety of encoding schemes. Moreover, these schemes may provide some guidance in identifying the neural mapping of tone CSs, at least as they pertain to classical conditioning of the rabbit NM response.

To illustrate an improved mapping scheme, it is necessary to understand in more detail how a CR may be generated by a sequence of stimulus elements. Figure 7 shows a schematic version of a real-time model (Kehoe et al., 1993). The top panel shows the time course of 10 stimulus elements during a CS. Each element rises in intensity $\left(X i_{t}\right)$ and then decays. The associative strength ( $V i)$ acquired by each element is assumed to be proportional to its intensity at the point of US delivery. To match the present experiments, the simulated point of US delivery was $800 \mathrm{msec}$ after CS onset. Accordingly, the middle panel shows the moment-by-moment product of each element's associative strength and its momentary intensity $\left(V i X i_{t}\right)$. The bottom panel shows the simulated time course of the CR generated by summing across the products for each element at each moment $t$ and subtracting a threshold value of 1.50--namely, $\left(\Sigma V i X i_{t}\right)-1.50$. The positive values of this expression are plotted. The simulated CR displays the key features of the CRs to the steady CSs in the present experiments. First, the simulated CR is anticipatory. Because each element stretches over a portion of the CS, the associative strength of an element is not confined to the point of US delivery, but is spread around that point. The initiation of the CR appears $350 \mathrm{msec}$ after CS onset. Second, the peak of the CR occurs at $900 \mathrm{msec}$, a point shortly after US delivery. At that point, the elements with the greatest associative strength coincide with each other. 

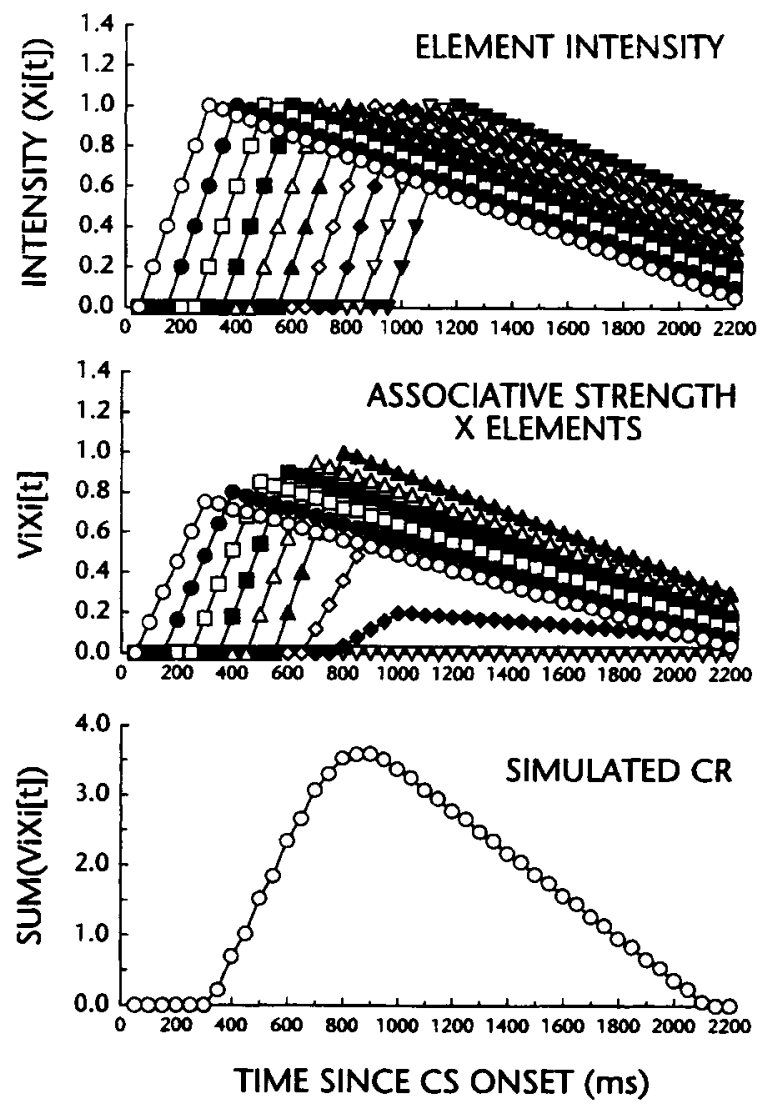

Figure 7. Schematic real-time model for a $\mathrm{CR}$ acquired using an 800-msec CS-US interval. The top panel shows the momentary intensities of 10 stimulus elements following CS onset. The middle panel shows the time course of the elements weighted by their respective associative strengths. The bottom panel shows the simulated CR that results when the weighted elements are summed.

\section{Moment-by-Moment Mapping and its Problems}

Like its more elaborate cousins, this schematic realtime model does not make any strong assumptions about the mapping between the sensory characteristics of the CS and its hypothetical elements. In the absence of strong assumptions, one point of departure is to assume that a tone's momentary characteristics are mapped more or less instantaneously into the array of stimulus elements. For example, the overall intensity of a tone CS can be readily encoded by multiplying the values of $X i_{t}$ with a constant $(\gamma)$. Thus, for each element at each moment $(t)$, the output variable became $V i X i_{t} \gamma$. For Experiment 2, $\gamma$ constants were fitted by search to the CRs for the steady-tone intensities of 60,75 , and $90 \mathrm{~dB}$. The parameter search yielded $\gamma$ constants of $.92, .98$, and 1.10, respectively. Using these constants, the simulated onset latencies were 400,350 , and $300 \mathrm{msec}$, which compared well to the actual mean onset latencies of 379,340 , and $276 \mathrm{msec}$, respectively. The simulated peak latencies were uniformly $850 \mathrm{msec}$, which compared well with the mean peak latencies of 818,865 , and $846 \mathrm{msec}$, respectively. Finally, the simulated peak amplitudes were 2.81 ,
3.39 , and $4.66 \mathrm{~mm}$, and the actual mean peak amplitudes were $2.84,3.38$, and $4.64 \mathrm{~mm}$.

Although it was easy to fit the schematic model to the results of the steady-tone CSs, it was difficult to reproduce the acceleration in the CRs obtained using tones with ascending or descending intensities. As a first attempt, the $\gamma$ constants fitted to the steady CSs were used to scale the 10 stimulus elements in the schematic model. Specifically, to create the ascending tone, the intensities of the 1 st element $\left(X 1_{t}\right)$ were multiplied by .92 , the $\gamma$ constant for the $60-\mathrm{dB}$ tone. The intensities of the 10 th element $\left(X 10_{t}\right)$ were multiplied by 1.10 , the $\gamma$ constant for the 90-dB tone. The scale values for all the other elements were computed by using linear interpolation. To create the descending tone, the sequence of scale values was simply reversed. Simulated testing with these changing tones had little impact on the time course of the simulated CRs. The simulated onset latencies remained around $350 \mathrm{msec}$, and the simulated peak latencies remained firmly planted at $850 \mathrm{msec}$.

Using this strategy, the model could accelerate the CR only by assigning arbitrarily large $X i$ intensities to the early elements on test trials. Figure 8's top panel shows the 10 elements when the $1 \mathrm{st}, 2 \mathrm{nd}$, and 3rd elements were assigned values of $5.0,1.5$, and 0.5 , respectively. The remaining elements were all assigned values of 0.1 . Thus, on simulated tests, the modest associative strengths of the early elements were amplified greatly, and the larger associative strengths of later elements were suppressed. The associative strengths were the same as those used to generate Figure 7. Figure 8's bottom panel shows the simulated CR that resulted from this parameter selection. The simulated CR onset latency was $200 \mathrm{msec}$, the CR peak latency was $450 \mathrm{msec}$, and the peak amplitude was $3 \mathrm{~mm}$. Thus, manipulations of the elements' intensities can yield an accelerated CR, but only in a patently ad hoc fashion.

When we attempted to simulate the acceleration of CRs in Experiment 1, in which tone frequency was manipulated, we ran into the same problems we had encountered with tone intensity. For the steady-tone CSs, all three frequencies produced similar CRs. Accordingly, there was no need to scale the overall intensity of the elements. For tests with tones of ascending or descending frequencies, the moment-by-moment generalization from each element's training frequency to its test frequency was scaled by using a generalization constant $(f)$ with values between 1.0 (identity) to 0.0 (no generalization). For example, a series of $f$ values that started at 1.0 and ended at 0.0 was used to simulate test tones that began at the frequency in training and finished at another frequency. For example, such a series was used to simulate the test tone in Group F500 that began at $500 \mathrm{~Hz}$ and ascended to $1500 \mathrm{~Hz}$. The same series of values was used for the test tone in Group F1500 that began at $1500 \mathrm{~Hz}$ and descended to $500 \mathrm{~Hz}$.

Simulations using constants restricted to $f$ values between 1.0 and 0.0 yielded no acceleration in the simu- 


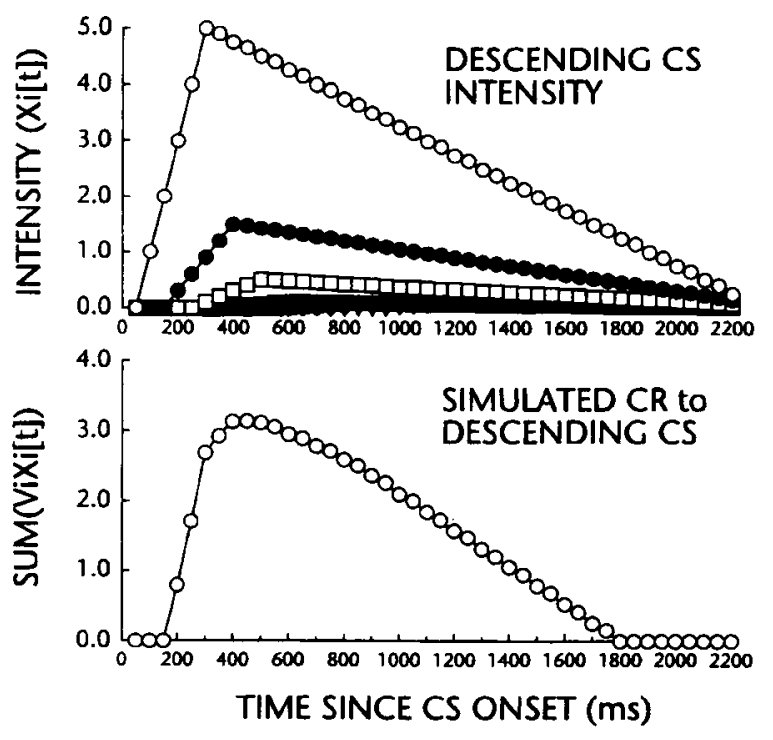

Figure 8. Modeling the CR to a modulated tone intensity by using differentially weighted elements. The top panel shows the momentary intensities of 10 stimulus elements. The bottom panel shows the simulated CR.

lated CRs. Because the $f$ value for most elements was less than 1.0 , the summated output variables $\sum V i X i_{f} f$ often failed to reach the threshold value (1.5) needed to produce a CR in the model. When the threshold was removed, some acceleration was seen only when a rapidly descending series was used. Specifically, the first element was assigned an $f$ value of 1.0 , the second element was assigned an $f$ value of 0.5 , and the other elements were assigned $f$ values of 0.01 . Using this series, the maximum output was moved to $400 \mathrm{msec}$, but its amplitude was only 1.03 , well below the ordinary threshold value for this model. With or without the threshold, no other series of $f$ values accelerated the CR.

\section{A Neural-Based Encoding Scheme}

From a neural perspective, a moment-by-moment mapping scheme can be viewed as roughly imitating the encoding of sounds that occurs at the level of the auditory nerve. At that level, moment-by-moment frequency and amplitude of the waveform are largely preserved (Møller, 1983, pp. 112-161; Sachs \& Blackburn, 1991). At higher levels in the auditory pathways, the encoding becomes more elaborate. In particular, the present findings suggest that parallel encodings of three different features of a tone determine the CR.

Onset firings. Sharp stimulus transitions yield bursts of neural activity throughout the auditory system (Caird, 1991; Disterhoft, Quinn, \& Weiss, 1987; Møller, 1983, pp. 159-162; Pfeiffer, 1966; Phillips, Reale, \& Brugge, 1991; Rhode, 1991; Tsuchitani \& Johnson, 1991). There are a variety of patterns activated by a brief tone. Some neurons fire for only tens of milliseconds following stimulus onset. Others show an initial burst followed by more sustained firing. Still others show an initial burst, a pause, and then a build up in the rate of firing, whereas others show a damped oscillation in their firing pattern. Many neurons are tuned to particular frequencies, but other neurons seem to encode only the occurrence of an acoustic stimulus regardless of its spectral composition (Irvine \& Jackson, 1983). These bursts may be the neural substrate of stimulus elements that allow the CR to proceed on its course even when the CS is truncated.

Modulation firings. Although the time course of the $\mathrm{CR}$ can rely largely on stimulus transitions, the present results revealed that the CR's time course is sensitive to modulations in the amplitude and frequency of the tone $\mathrm{CS}$. The auditory nervous system is, in fact, highly responsive to sound modulations and has a rich encoding scheme for them. Many neurons that respond to fixed tones are even more responsive to tones that are modulated in either amplitude or frequency. Some neurons are sensitive to the direction of the change, and others are indifferent (Møller, 1983, pp. 166-174; Phillips et al., 1991; Rhode, 1991; Whitfield \& Evans, 1965).

The extra responsiveness of auditory neurons to modulated tones may underpin the acceleration in CRs evoked by the changing tones in Experiments 1 and 2 . With reference to the schematic model, it is likely that a number of neurons must be firing to activate the stimulus elements in the sequence. Because many neurons are highly responsive to a modulated tone, the ascending and descending test tones would activate more neurons sooner than the steady-tone CS. For example, rapid amplitude increments help synchronize afferent neural inputs (Phillips et al., 1991). The same appears true for changes in frequency in either direction (Møller, 1983, pp. 267-268). In theoretical terms, the sequence of elements would be accelerated during a modulated tone, and hence the CRs would also be accelerated. To illustrate this point, Figure 9 shows the pattern of stimulus elements and the resulting CR when the sequence of elements has been run off more rapidly than on training trials. As can be seen in comparison with Figure 7, the $\mathrm{CR}$ has been accelerated by compressing the stimulus sequence in time.

Frequency and amplitude-related firings. Although neural encodings related to tone onset and modulation may govern the CR's time course, the frequency and amplitude of steady tones are relevant to conditioning. In the rabbit NM preparation, the frequency and amplitude of tone CSs have well-established effects on the likelihood and amplitude of CRs (e.g., Kehoe \& Napier, 1991b; Moore, 1972). However, CS frequency has little effect on the time course of the CR. For example, Kehoe and Napier (1991b, Experiment 3) trained rabbits with a tone of fixed frequency $(400$ or $4800 \mathrm{~Hz}$ ). The rabbits were tested with tones with frequencies of 400,1800 , 3300 , and $4800 \mathrm{~Hz}$. The likelihood of the CRs decreased progressively, depending on the difference between the training and test frequencies. However, the CR onset latency and peak latency remained largely unchanged. 

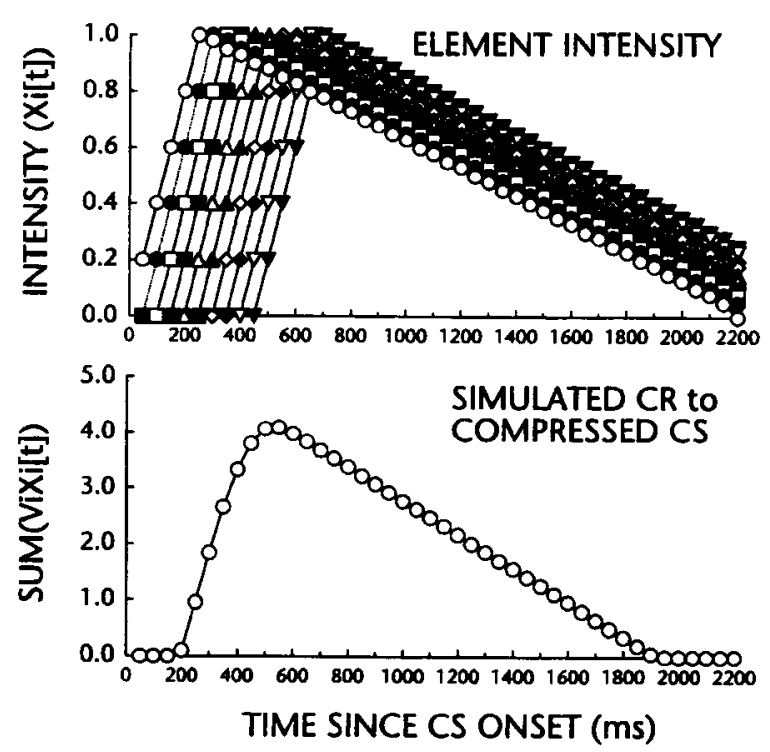

Figure 9. Modeling the $\mathrm{CR}$ to a modulated tone by accelerating the onset times of the stimulus elements. The top panel shows the momentary intensities of 10 stimulus elements. The bottom panel shows the simulated $\mathbf{C R}$.

\section{Conclusions}

The present findings are the first time that manipulations of a tone CS have so dramatically altered the time course of a CR. Previous manipulations of tone duration and tone frequency have had little impact on CR timing (Kehoe \& Napier, 1991a, 1991b). Similarly, when the CS has contained a series of acoustic events, test manipulations have included dropping events and reversing their order. In neither case was the CR timing affected in more than a marginal fashion. Thus, it appeared that tone onset largely governed CR timing by activating a sequence of stimulus elements. Now, it is clear that modulation of a tone CS has a huge impact on CR timing. Consequently, real-time models of CR generation need to incorporate stimulus sequences that are sensitive to modulation of tone frequency and amplitude.

From a neural perspective, the present results may help to localize the auditory encodings that underpin the time course of the CR. Pathways for conditioning in the NM preparation run through the brain stem and cerebellum. In these pathways, the pontine nuclei are a critical relay for the transmission of tonal CSs through mossy fibers to cerebellar nuclei that are essential to the acquisition and performance of the CR. Moreover, the mossy fibers arising from the pontine nuclei may constitute a tapped delay line that would supply the sequence of stimulus elements needed for timing the CR (Moore \& Desmond, 1992). The pontine nuclei receive inputs from several points in the auditory pathways (Brodal \& Bjaalie, 1992), including the cochlear nucleus in the rabbit (J. K. Thompson, Lavond, \& R. F. Thompson, 1986; J. K. Thompson, Lavond, Weiss, \& R. F. Thompson, 1988), the inferior colliculus in the cat (Kawamura,
1975), and the auditory cortex in the rabbit (Knowlton, J. K. Thompson, \& R. F. Thompson, 1993). By systematically isolating the pontine nuclei from one or more of these auditory nuclei, it should be possible to identify which of the auditory nuclei provide the encodings of sharp tone onsets and/or the slow modulations of frequency and amplitude. In a similar fashion, it may be possible to isolate noncerebellar structures that have also been implicated in CR timing - for example, the hippocampus (Berger, Weikart, Bassett, \& Orr, 1986; Hoehler \& R. F. Thompson, 1980; Port, Mikhail, \& Patterson, 1985).

\section{REFERENCES}

Berger, T. W., \& Thompson, R. F. (1978). Neuronal plasticity in the limbic system during classical conditioning of the rabbit nictitating membrane response: I. The hippocampus. Brain Research, 145, 323-346.

Berger, T. W., Weikart, C. L., Bassett, J. L., \& OrR, W. B. (1986). Lesions of the retrosplenial cortex produce deficits in reversal learning of the rabbit nictitating membrane response: Implications for potential interactions between hippocampal and cerebellar brain systems. Behavioral Neuroscience, 100, 802-809.

Berthier, N. E., \& Moore, J. W. (1986). Cerebellar Purkinje cell activity related to the classically conditioned nictitating membrane responses. Experimental Brain Research, 63, 341-350.

Brodal, P., \& BJaAlie, J. G. (1992). Organization of the pontine nuclei. Neuroscience Research, 13, 83-118.

CaIrD, D. (1991). Processing in the colliculi. In R. A. Altschuler, B. P. Bobbin, B. M. Clopton, \& D. W. Hoffman (Eds.), Neurobiology of hearing: The central auditory system (pp. 253-292). New York: Raven Press.

Cegavske, C. F., Patterson, M. M., \& Thompson, R. F. (1979). Neuronal unit activity in the abducens nucleus during classical conditioning of the nictitating membrane response in the rabbit (Oryctolagus cuniculus). Journal of Comparative \& Physiological Psychology, 93, 595-609.

Coleman, S. R., \& Gormezano, I. (1971). Classical conditioning of the rabbit's (Oryctolagus cuniculus) nictitating membrane response under symmetrical CS-US interval shifts. Journal of Comparative \& Physiological Psychology, 77, 447-455.

DESMOND, J. E. (1990). Temporal adaptive responses in neural models: The stimulus trace. In M. Gabriel \& J. W. Moore (Eds.), Learning and computational neuroscience (pp. 421-456). Cambridge, MA: MIT Press.

Desmond, J. E., \& MoORE, J. W. (1988). Adaptive timing in neural networks: The conditioned response. Biological Cybernetics, 58, 405415.

DESMOND, J. E., \& MOORE, J. W. (1991). Altering the synchrony of stimulus trace processes: Tests of a neural-network model. Biological Cybernetics, 65, 161-169.

DisterhoFT, J. F., QuinN, K. J., \& Weiss, C. (1987). Analyses of the auditory input and motor output pathways in rabbit nictitating membrane conditioning. In I. Gormezano, W. F. Prokasy, \& R. F. Thompson (Eds.), Classical conditioning (3rd ed., pp. 93-116). Hillsdale, NJ: Erlbaum.

DisterhofT, J. F., QuinN, K. J., Weiss, C., \& ShiPley, M. T. (1985). Accessory abducens nucleus and conditioned eye retraction/nictitating membrane extension in rabbit. Journal of Neuroscience, $\mathbf{5}$, 941-950.

Gormezano, I. (1966). Classical conditioning. In J. B. Sidowski (Ed.), Experimental methods and instrumentation in psychology (pp. 385420). New York: McGraw-Hill.

GoRmEZANO, I. (1972). Investigations of defense and reward conditioning in the rabbit. In A. H. Black \& W. F. Prokasy (Eds.), Classical conditioning II: Current research and theory (pp. 151-181). New York: Appleton-Century-Crofts.

Gormezano, I., \& Gibbs, C. M. (1988). Transduction of the rabbit's 
nictitating membrane response. Behavior Research Methods, Instruments, \& Computers, 20, 18-21.

Gormezano, I., \& Kehoe, E. J. (1981). Classical conditioning and the law of contiguity. In P. M. Harzem \& M. D. Zeiler (Eds.), Advances in analysis of behavior: Vol. 2. Predictability, correlation, and contiguity (pp. 1-45). New York: Wiley.

Gormezano, I., Kehoe, E. J., \& Marshall, B. S. (1983). Twenty years of classical conditioning research with the rabbit. In J. M. Sprague \& A. N. Epstein (Eds.), Progress in psychobiology and physiological psychology (pp. 197-275). New York: Academic Press.

Grossberg, S., \& Schmajuk, N. A. (1989). Neural dynamics of adaptive timing and temporal discrimination during associative learning. Neural Networks, 2, 79-102.

Hoehler, F. K., \& Thompson, R. F. (1980). Effect of the interstimulus (CS-UCS) interval on hippocampal unit activity during classical conditioning of the nictitating membrane response of the rabbit (Oryctolagus cuniculus). Journal of Comparative \& Physiological Psychology, 94, 201-215.

Hull, C. L. (1937). Mind, mechanism and adaptive behaviors. Psychological Review, 44, 1-32.

Hull, C. L. (1943). Principles of behavior. New York: AppletonCentury-Crofts.

Hul , C. L. (1952). A behavior system. New Haven, CT: Yale University Press.

IRviNE, D. R. F., \& JACKSON, G. D. (1983). Auditory input to neurons in mesencephalic and rostral reticular formation: An electrophysiological and horseradish peroxidase study in the cat. Journal of Neurophysiology, 49, 1319-1333.

James, G. O., Hardiman, M. J., \& Yeo, C. H. (1987). Hippocampal lesions and trace conditioning in the rabbit. Behavioural Brain Research, 23, 109-116.

KaWAmura, K. (1975). The pontine projection from the inferior colliculus in the cat: An anatomical study. Brain Research, 95, 309322.

KEHOE, E. J. (1982). Overshadowing and summation in compound stimulus conditioning of the rabbit's nictitating membrane response. Journal of Experimental Psychology: Animal Behavior Processes, 8, 313-328.

Kehoe, E. J., Graham-Clarke, P., \& Schreurs, B. G. (1989). Temporal patterns of the rabbit's nictitating membrane response to compound and component stimuli under mixed CS-US intervals. $B e$ havioral Neuroscience, 103, 283-295.

Kehoe, E. J., Horne, P. S., Macrae, M., \& Horne, A. J. (1993). Realtime processing of serial stimuli in classical conditioning of the rabbit's nictitating membrane response. Journal of Experimental Psychology: Animal Behavior Processes, 19, 265-283.

KEHOE, E. J., \& NAPIER, R. M. (1991a). In the blink of an eye: Real time stimulus factors in delay and trace conditioning of the rabbit's nictitating membrane response. Quarterly Journal of Experimental Psychology, 43B, 257-277.

KeHOE, E. J., \& NAPIER, R. M. (1991b). Real-time factors in the rabbit's nictitating membrane response to pulsed and serial conditioned stimuli. Animal Learning \& Behavior, 19, 195-206.

KEHOE, E. J., \& SChreurs, B. G. (1986). Compound-component differentiation as a function of CS-US interval and CS duration in the rabbit's nictitating membrane response. Animal Learning \& Behavior, 14, 144-154.

Knowlton, B. J., Thompson, J. K., \& Thompson, R. F. (1993). Projections from the auditory cortex to the pontine nuclei in the rabbit. Behavioural Brain Research, 56, 23-30.

Marshall-Goodell, B., Frei, L., \& Gormezano, I. (1989). A personal computer programmable sine-wave generator. Behavior Research Methods, Instruments, \& Computers, 21, 431-434.

Marshall-Goodell, B., Schreurs, B. G., \& Gormezano, I. (1982). Ruler vs. the Apple II/FIRST system analysis of analog signals in classical conditioning. Behavior Research Methods \& Instrumentation, 14, 519-525

MaUK, M. D., \& RuIz, B. P. (1992). Learning-dependent timing of Pavlovian eyelid responses: Differential conditioning using multiple interstimulus intervals. Behavioral Neuroscience, 106, 666-681.
McCormick, D., \& Thompson, R. F. (1984). Neuronal responses of the rabbit cerebellum during acquisition and performance of a classically conditioned nictitating membrane-eyelid response. Journal of Neuroscience, 4, 2811-2822.

Millenson, J. R., Kehoe, E. J., \& Gormezano, I. (1977). Classical conditioning of the rabbit's nictitating membrane response under fixed and mixed CS-US intervals. Learning \& Motivation, 8, 351 366.

Møller, A. R. (1983). Auditory physiology. San Diego, CA: Academic Press.

MoOre, J. W. (1972). Stimulus control: Studies of auditory generalization in rabbits. In A. H. Black \& W. F. Prokasy (Eds.), Classical conditioning II: Current research and theory (pp. 206-230). New York: Appleton-Century-Crofts.

MoOre, J. W., \& BerThIER, N. E. (1987). Purkinje cell activity and the conditioned nictitating membrane response. In M. Glickstein, C. Yeo, \& J. Stein (Eds.), Cerebellum and neuronal plasticity (pp. 339-352). New York: Plenum.

MOORE, J. W., \& DESMOND, J. E. (1992). A cerebellar neural network implementation of a temporally adaptive conditioned response. In I. Gormezano (Ed.), Learning and memory: The biological substrates (pp. 347-368). Hillsdale, NJ: Erlbaum.

Moyer, J. R., Deyo, R. A., \& Disterhort, J. F. (1990). Hippocampectomy disrupts trace eye-blink conditioning in rabbits. Behavioral Neuroscience, 104, 243-252.

Pavlov, I. P. (1927). Conditioned reflexes (G. V. Anrep, Trans.). London: Oxford University Press.

PfEIfFER, R. R. (1966). Classification of response patterns of spike discharges for units in the cochlear nucleus: Tone-burst stimulation. Experimental Brain Research, 1, 220-235.

Phillips, D. P., Reale, R. A., \& Brugge, J. F. (1991). Stimulus processing in the auditory cortex. In R. A. Altschuler, B. P. Bobbin, B. M. Clopton, \& D. W. Hoffman (Eds.), Neurobiology of hearing: The central auditory system (pp. 335-365). New York: Raven Press.

Port, R. L., Mikhail, A. A., \& Patterson, M. M. (1985). Differential effects of hippocampectomy on classically conditioned rabbit nictitating membrane response related to interstimulus interval. Behavioral Neuroscience, 99, 200-208.

Port, R. L., Romano, A. G., Steinmetz, J. E., Mikhail, A. A., \& PatTERSON, M. M. (1986). Retention and acquisition of classical traceconditioned responses by rabbits with hippocampal lesions. Behavioral Neuroscience, 100, 745-752.

RHode, W. S. (1991). Physiological-morphological properties of the cochlear nucleus. In R. A. Altschuler, B. P. Bobbin, B. M. Clopton, \& D. W. Hoffman (Eds.), Neurobiology of hearing: The central auditory system (pp. 47-77). New York: Raven Press.

SaChs, M. B., \& Blackburn, C. C. (1991). Processing of complex sounds in the cochlear nucleus. In R. A. Altschuler, B. P. Bobbin, B. M. Clopton, \& D. W. Hoffman (Eds.), Neurobiology of hearing: The central auditory system (pp. 79-98). New York: Raven Press

Salafia, W. R., Martino, L. J., Cloutman, K., \& Romano, A. G (1979). Unconditional-stimulus locus and interstimulus-interval shift in rabbit (Oryctolagus cuniculus) nictitating membrane conditioning. Pavlovian Journal of Biological Science, 14, 64-71.

SCANDRETT, J., \& GoRmEZANo, I. (1980). Microprocessor control and A/D data acquisition in classical conditioning. Behavior Research Methods \& Instrumentation, 12, 120-125.

Scavio, M. J., \& GoRmEZaNo, I. (1974). CS intensity effects upon rabbit nictitating membrane conditioning, extinction, and generalization. Pavlovian Journal of Biological Sciences, 9, 25-34.

SMITH, M. C. (1968). CS-US interval and US intensity in classical conditioning of the rabbit's nictitating membrane response. Journal of Comparative \& Physiological Psychology, 66, 679-687.

Solomon, P. R., Vander SchaAf, E. R., Weisz, D. J., \& Thompson, R. F. (1986). Hippocampus and trace conditioning of the rabbit's classically conditioned nictitating membrane response. Behavioral Neuroscience, 100, 729-744.

Sutton, R. S., \& Barto, A. G. (1990). Time-derivative models of Pavlovian reinforcement. In M. Gabriel \& J. W. Moore (Eds.), Learning and computational neuroscience (pp. 497-537). Cambridge, MA: MIT Press. 
Thompson, J. K., Lavond, D. G., \& Thompson, R. F. (1986). Preliminary evidence for a projection from the cochlear nuclei to the pontine nuclear region. Society for Neuroscience Abstracts, 12, 754.

Thompson, J. K., Lavond, D. G., Weiss, C., \& Thompson, R. F. (1988). Pontine projections of the cochlear nuclei using anterograde HRP or PHA-L. Society for Neuroscience Abstracts, 14, 782.

TsuChitani, C., \& Johnson, D. H. (1991). Binaural cues and signal processing in the superior olivary complex. In R. A. Altschuler, B. P. Bobbin, B. M. Clopton, \& D. W. Hoffman (Eds.), Neurobiology of hearing: The central auditory system (pp. 163-193). New York: Raven Press.

Weisz, D. J., ClaRK, G. A., \& Thompson, R. F. (1984). Increased responsivity of dentate granule cells during nictitating membrane re- sponse conditioning in the rabbit. Behavioural Brain Research, 12, 145-154.

WhITFIELD, I. C., \& EVANS, E. F. (1965). Responses of auditory cortical neurons to stimuli of changing frequency. Journal of Neurophysiology, 28, 655-672.

Young, R. A., Cegavaske, C. F., \& Thompson, R. F. (1976). Tone-induced changes in excitability of abducens motoneurons and of the reflex path of the nictitating membrane response in rabbit (Oryctolagus cuniculus). Journal of Comparative \& Physiological Psychology, 90, 424-434.

(Manuscript received May 26, 1994; revision accepted for publication August 20, 1994.) 